\title{
Leaders and their supreme contributions for the organizational greatness
}

\begin{abstract}
Leadership is undoubtedly the pivotal ability of mind and an advanced reflection of thoughtful steps in deed. From the perspective of an organization leaders do take the prime initiative to regulate the organizational flow as per the organizational flow and regulations. On the other hand it is absolutely evident that leaders do exhibit their compassionate zeal and guide their flowers and subordinates towards the pre-determined occupational pinnacle in a befitting manner. This is an incredible understanding in between leaders and followers just not do lead themselves for their own occupational settlements but for the qualitative organizational procurements within a short while. Most notably both leaders and followers shall have to be truly responsive to understand the needful organizational paradigm and real organizational need. Therefore leaders do create this crucial understanding in terms of enriching their professional stature and the propensity to hard work begins from there. Leaders do perceive that it is one of the prompt measures to be exclusively accomplished right from the beginning.
\end{abstract}

Keywords: leader's depth, leader's contribution, organizational core, organizational advancement
Volume 2 Issue 5 - 2018

\author{
DR. Rudrarup Gupta \\ Commercial Manager, Multifarious Projects Group, Kolkata, India
}

Correspondence: Rudrarup Gupta, Commercial Manager, Multifarious Projects Group, Kolkata, India, Email rudrarupgupta2I@gmail.com

Received: August 06, 2018 | Published: September 18,2018

\section{Introduction}

Leaders do have the beautiful occupational virtuosity, which can inspire their followers and subordinates in wide-eyed movements in deed. Most importantly leaders try to understand the primacy of organizational sustainability and they do prepare their subordinates accordingly.

In other words each worker must understand what exactly they are going to invest their very expensive energies for. Because each contribution should have an inhabitable outcome from the perspective of their gradual learning and the upstanding growth of organization as well.

Al-Malki Mohammed \& Juan Wang ${ }^{1}$ have told (2018) have told in one of the research discussions that, the great leadership styles, which are the key attributes for job performance. Moreover this paper says leaders do invariably expect an exclusive impact from their team members who are really the key for their organizational job performance in deed.

Therefore leaders do have some unbeatable attributes in their minds, which are as follows:

1. Cultural nicety: it is having a purposeful consequence from both the ends of leaders and followers. Because all the followers do perform under the leadership of leaders in enriching their occupational goal. So this activities do take place in such disciplined manner, each performer can have an ample space to raise their views and this is how an understanding is grown over there, which is the prime alert to maintain this nicety in style.

2. Desire to work: it is very important from the perspective of successful organizational outcome. That is why leaders do create an astounding desire amongst all the followers, who are the core strength to enhance the annual productivity of an organization.

3. Willingness to learn: Learning is a very notable practice not only for self refinement but for the wide-open productive outreach for an organization. In this regard leaders do increase the will power of their employees through different trainings, evaluations, estimations and so on. So that it is really profitable for employees to be in that track and to be accomplished accordingly.

4. Proper understanding: Leaders are very concerned about the same. Because this understanding can increase the volume of outcome and the extensive job satisfaction. That is why each follower has to understand each and other just to be in the same professional zeal for the utmost benefit.

5. Fellow Feeling: It is originated from humanity. Each of the followers should have the same just to ensure the desired occupational spark with words and wisdom. On the other hand it is really easier for a leader to form an elite synthesis where the scrupulous professional benchmarks are just a matter of time.

Day David V \& Dragoni Lisa ${ }^{2}$ have expressed their view (2015) in one of the journals that, some organizations of same category do face undeniable challenges, which are related with leadership capacities. Though present research studies have responded really well upon leadership but early stages of scientific development is still alive to represent our modern research in deed.

\section{Key cautions}

a) Need: Leaders shall have to understand the real organizational need. Because this need shall navigate the path way and ensure the organizational success as well. That is why understanding the need is an outstanding avenue to lead upon and to fulfill the same is a life time occupational attainment to reach in.

b) Assessment: Leaders are in a position to assess their selves and their immediate followers. It can secure the progress and leader's judgment towards the followers and their decisive destiny. So leaders are very particular to assess both theoretical and practical concepts of an organization in deed. In other words leaders do implement the same for the unparallel professional pathway according to their progressive mind frame.

c) Progress: It is one of the vital aspects and it has to be exclusively evaluated right from the beginning. Because each pivotal step is initiated for progress and leaders do take the requisite initiative 
for this unstoppable progress for satisfying the followers and the true organizational existence in all the regards.

Iqbal N, Anwar S \& Haider $\mathrm{N}^{3}$ have told in their article that, this study signifies the effect of leadership styles, which have been truly highlighted upon the employee performance in an organization. Most notably the intention of this study is to classify the various leadership styles for enriching the employee performance in deed.

\section{Conclusion}

Leaders are the commendable resource to drive an organization for the gleeful occupational vertex, where each follower is based upon participative leadership approach and its elevating organizational splendor.

\section{Acknowledgments}

None.

\section{Conflict of interest}

Author declares there is no conflict of interest.

\section{References}

1. Al Malki Mohammad, Juan Wang. Leadership Styles and Job Performance. Journal of International Business Research and Marketing. 2018;3(3):40-49.

2. Day David V, Dragoni Lisa. Leadership Development: An Outcome Oriented Review Based on Time and Levels of Analysis. Annual Review of Organizational Psychology and Organizational Behavior. 2015;2:133-156.

3. Iqbal N, Anwar S, Haider N, et al. Effect of Leadership Style on Employee Performance. Arabian Journal of Business and Management Review. 2015;5:146. 